\title{
PERANCANGAN SISTEM APLIKASI PENGOLAHAN DATA TRANSAKSI DAN INVOICE PADA PT. WAHANA ELEKSIA TECHNOLOGY BERBASIS JAVA
}

\author{
Ayu Nur Afriani \\ Teknik Informatika,Fakultas Ilmu Komputer, Universitas Indraprasta PGRI Jakarta \\ Jalan Raya Tengah No 80, Kelurahan Gedong, Pasar Rebo, Jakarta Timur \\ afrianiayu10@gmail.com
}

\begin{abstract}
ABSTRAK
Permasalahan yang terdapat pada PT. Wahana Eleksia Technology adalah terjadinya kesalahan dalam pengolahan data-data transaksi dan proyek yang masih menggunakan proses manual dengan menuliskan nya didalam Microsoft Excel sehingga sering terjadi kesalahan data atau pun data yang tidak tercatat. Tujuan merancang suatu sistem aplikasi data transaksi dan invoice ini dengan tujuan untuk menghindarkan admin dan staf finance dalam memproses pengolahan data yang ada saat ini hingga sampai ke tahap pelaporan. Aplikasi yang telah dibuat dengan bahasa pemrograman Java NetBeans 8.0.2 dan penyimpanan data pada database MySQL dapat memberikan kelancaran dalam proses menginput dan penyimpanan data-data serta laporanlaporan yang diberikan kepada pimpinan perusahaan. Dengan menggunakan metode pengembangan sistem yaitu Waterfall dalam penelitian ini adalah dengan tahapan-tahapan seperti rekayasa sistem, analisis, desain, implementasi, testing, dan pemeliharaan. Hasil akhir dari penelitian ini adalah merancang aplikasi pengolahan data transaksi dan invoice secara terkomputerisasi sehingga dapat membantu proses penagihan dan monitoring proyek yang sedang berlangsung yang tersaji dalam bentuk aplikasi program berbasis desktop sehingga prosesnya menjadi lebih baik dan efisien.
\end{abstract}

Kata Kunci: Aplikasi, Transaksi, Data, Invoice, Desktop

\section{ABSTRACT}

The problems that exist in PT. Wahana Eleksia Technology is an error in processing transaction and project data that still uses a manual process by writing it in Microsoft Excel so that data errors or data are not recorded frequently. The purpose of designing an application system for transaction data and invoices is to prevent admin and finance staffrom processing the current data processing up to reporting. Application tools that have been created using the Java NetBeans 8.0.2 programming language and data storage in the MySQL database can provide smooth processing of input and storage of data and reports provided to company leaders. By using the system development method, namely Waterfall, in this research, the stages are systems engineering, analysis, design, implementation, testing, and maintenance. The final result of this research is to design a computerized transaction and invoice data processing application so that it can assist the billing process and ongoing project monitoring which is presented in the form of a desktop-based program application so that the process becomes better and more efficient.

Key Word: Application, Transaction, Data, Invoice, Desktop

\section{PENDAHULUAN}

Perkembangan teknologi dan komputer tumbuh dengan sangat pesat terutama pada bidang komputer. Selain digunakan sebagai alat untuk mencari informasi, komputer juga dapat digunakan untuk mengolah data yang dapat berguna bagi perkembangan komputer itu sendiri maupun yang menggunakan. Dewasa ini sudah banyak pekerjaan yang dilakukan secara manual dapat digantikan oleh komputer untuk mempersingkat waktu kerja serta dapat bekerja secara akurat, efisien, cepat dan tepat. Sama halnya yang terjadi di PT. Wahana Eleksia Technology dalam hal pengolahan data transaksi maupun invoice masih dilakukan secara manual, hal tersebut sering menimbulkan beberapa permasalahan. Oleh karena itu perlu adanya sistem terkomputerisasi yang berfungsi untuk mengolah data transaksi, proyek maupun invoice sehingga membantu pihak manajemen dalam memperoleh informasi atau laporan data secara efisien. Sutabri (2012) menyatakan bahwa Sistem merupakan suatu bentuk integrasi antara satu komponen dengan komponen lain karena sistem memiliki sasaran yang berbeda untuk setiap kasus yang terjadi dalam suatu sistem. Sedangkan Susanto (2013) menyatakan bahwa Sistem adalah kumpulan / 
group dari sub sistem/komponen apa saja baik fisik maupun non fisik yang saling berhubungan satu dengan yang lain dan saling bekerja sama secara terpadu untuk mencapai tujuan tertentu.

Diharapkan dengan adanya suatu sistem informasi dapat menangani permasalahan yang ada di perusahaan. Sistem adalah setiap sesuatu terdiri dari obyek-obyek, atau unsur-unsur, atau komponen-komponen yang bertata kaitan dan bertata hubungan satu sama lain, sedemikian rupa sehingga unsur-unsur tersebut merupakan satu kesatuan pemrosesan atau pengolahan yang tertentu (Prasojo, 2011).

Aplikasi adalah suatu program yang dibuat untuk melaksanakan fungsi bagi pengguna jasa serta bagi penggunaan aplikasi lain yang dapat digunakan oleh suatu sasaran yang dituju. Aplikasi tersebut dapat membantu proses pencatatan data transaksi dan invoice yang sering kali terjadi kesalahan dalam presentase penagihan maupun pekerjaan yang terlewat belum dilakukan penagihan. Menurut Yuhefizar (2012) Aplikasi merupakan program yang dikembangkan untuk memenuhi kebutuhan pengguna dalam menjalankan pekerjaan tertentu. Sedangkan menurut Asropudin (2013) Aplikasi adalah software yang dibuat oleh suatu perusahaan komputer untuk mengerjakan tugas-tugas tertentu.

Mengingat pentingnya data transaksi dalam keberlangsungan suatu perusahaan, diperlukan sinergi dalam pengolahan data antara admin dengan staf finance. Selain data transaksi ada komponen penting lainnya yaitu faktur atau invoice. Secara umum invoice atau faktur merupakan salah satu dokumen dasar sebagai bukti pencatatan penjualan dan pembelian bagi perusahaan penjual dan perusahaan pembeli.

Mursyidi (2010) Menyatakan bahwa Faktur ini merupakan bukti transaksi penjualan yang dilakukan secara kredit dan biasanya dibuat rangkap. Faktur sangatlah penting untuk menjaga aset suatu perusahaan dan untuk menghindari kecurangan-kecurangan yang akan timbul pada suatu perusahaan. Sedangkan menurut Sutabri (2012) sumber dari informasi adalah data. Data adalah kenyataan yang menggambarkan suatu kejadian-kejadian dan kesatuan nyata yang terjadi pada saat tertentu di dalam dunia bisnis. Sedangkan bisnis dapat diartikan sebagai perubahan dari suatu nilai yang disebut transaksi. Dapat dimisalkan seperti, penjualan merupakan transaksi perubahan nilai barang menjadi nilai uang atau nilai piutang dagang.

Pada PT. Wahana Eleksia Technology, dalam pengolahan data transaksi dan invoice masih kurang efektif dikarenakan pengelolaan data transaksi, proyek dan invoice masih di kelola secara manual, yaitu bagian staf admin menyerahkan dokumen kelengkapan invoice yang sudah selesai beserta Purchase Order-Nya ke bagian finance, lalu dibuatkan invoice yang berisi faktur pajak dan kuitansi. Pada bagian pembuatan kuitansi harus mencantumkan termin pembayaran dan nomer Purchase Order. Sehingga proses penagihan telambat karena kesalahan penginputan termin dan nominal penagihan, dan ini mempengaruhi cashflow perusahaan.

Oleh karena itu, tujuan penulis melakukan penelitian ini adalah membuat suatu sistem pengolahan data transaksi dan invoice yang mudah digunakan secara terkomputerisasi dan membuat suatu laporan dapat lebih cepat, akurat dan mudah.

Kegunaan penelitian yang diberikan dalam tugas akhir ini adalah membantu staf admin dalam melakukan pemantauan proyek yang sedang berjalan, dan divisi finance bisa memastikan termin penagihan sesuai dengan proyek yang berlangsung di lapangan. Serta dapat menyajikan laporan yang cepat, tepat dan akurat, berguna untuk evaluasi kinerja cashflow perusahaan.

\section{METODE PENELITIAN}

Tempat penelitian dilakukan pada PT. Wahana Eleksia Technology yang beralamatkan di Kawasan Pergudangan Bizhub Blok GG No. 7 Jalan Raya Serpong No. 99, Gunung Sindur Bogor.

Desain yang digunakan dalam penelitian ini yaitu metode air terjun atau yang sering disebut metode waterfall. Metode ini sering diberi nama siklus hidup klasik, dimana dalam hal ini menggambarkan suatu pendekatan yang 
berurutan dan juga sistematis pada pengembangan perangkat lunak, dimulai dari kebutuhan spesifikasi si pengguna lalu berlanjut melalui suatu tahapan-tahapan perencanaan (planning), permodelan (modeling), konstruksi (construction), serta penmberian sistem kepada pengguna (deployment), diakhiri dengan memberikan dukungan pada perangkat lunak yang dihasilkan secara lengkap (Pressman, 2012).

Dalam pengumpulan data penulis menggunakan teknik dalam pengumpulan data untuk penelitian antara lain:

Studi kepustakaan

1. Studi Kepustakaan

Data dan informasi dikumpulkan dari kutipankutipan buku-buku, artikel jurnal, hasil laporan dan bahan lainnya yang berkaitan dengan penelitian ini. Dari bahan-bahan tersebut kemudian diambil teori-teori yang dapat dijadikan suatu landasan untuk menganalisa masalah yang terjadi didalam penelitian.

\section{Studi Lapangan}

Pada Studi lapangan, penulis melihat langsung sistem penagihan dan pelaporan proyek yang menggunakan sistem manual (memasukkan data ke Ms. Excel). Dalam studi lapangan penulis menggunakan teknik pengumpulan data antara lain dengan cara :

Wawancara yaitu teknik pengumpulan data dengan bertanya langsung kepada staf admin dan finance yang mengerti dan paham mengenai proses penagihan dan pelaporan proyek. Metode wawancara merupakan metode yang sangat efektif dalam pengumpulan data. Penulis melakukan wawancara untuk mendapatkan data-data seperti data proyek dan invoice pada PT. Wahana Eleksia Technology.

Penulis bertanya kepada Project Manager yang paham tentang proses proyek yang sedang berlangung secara manual. Dari hasil wawancara tersebut penulis menyimpulkan bahwa membutuhkan waktu untuk melaporkan hasil kerja tersebut. Hal ini diakibatkan oleh sistem peng-input-an yang masih manual menggunakan Microsoft Excel. Harapan beliau kedepannya sistem yang berjalan sudah terkomputerisasi sehinga mempunyai sistem pengolahan data transaksi dan invoice yang lebih efektif dan juga efisien.

Observasi adalah melakukan pengamatan dan pencatatan secara sistematik kepada unsur-unsur yang muncul dalam suatu gejala dalam bentuk objek penelitian. Mendefinisikan observasi untuk memilih, mengubah dan juga pengodean serangkaian perilaku dalam susasana sesuai dengan tujuan empiris (Hikmat, 2011). Penulis melakukan observasi awal untuk mengumpulkan data-data yang dibutuhkan untuk analisa proses penilaian kinerja pegawai mulai bulan Maret.

\section{Langkah Pengembahangan Sistem}

Pada tahapan analisis dan definisi kebutuhan pengolahan data transaksi dan invoice penulis melakukan pengamatan terhadap sistem yang sedang berjalan dan konsultasi dengan Project Manager PT. Wahana Eleksia Technology mengenai masalah yang terjadi. Pada tahapan desain sistem dan perangkat lunak pengolahan data transaksi dan invoice dibentuk rancangan berdasarkan kebutuhan yang diinginkan oleh perusahaan. Pada tahapan implementasi dan pengujian, hasil dari desain perangkat lunak direalisasikan sehingga program-program membentuk satu set program dan diuji sesuai dengan kebutuhan pengolahan data transaksi dan invoice.

Pada tahapan integrasi dan pengujian sistem dilakukan untuk memastikan apakah semua fungsi sistem bekerja dengan baik dan mencari apakah masih ada kesalahan pada sistem. Pada tahap terakhir yaitu implementasi sistem dan pemeliharaan terdiri dari koreksi dari berbagai kesalahan yang tidak ditemukan di tahap-tahap sebelumnya, perbaikan atas implementasi dan pengembangan unit sistem, serta pemeliharaan program.

\section{HASIL DAN PEMBAHASAN}

\section{Alternatif Penyelesaian Masalah}

Alternatif pemecahan masalah yang akan penulis lakukan untuk mempermudah proses kerja pada PT.Wahana Eleksia Technology adalah:

1. Dibuatkan satu wadah atau sistem yang dapat diakses oleh setiap karyawan, sehingga semua staf dapat melakukan update project ataupun invoice di satu sistem. Dan juga dapat menghindari terjadinya redudan data atau terjadinya skip payment karena PO kadaluarsa, karena tim finance dapat melakukan pengecekan untuk setiap PO yang masuk. 
2. Merancang sistem aplikasi yang dapat membantu pihak admin untuk melakukan update proyek yang diterima atau yang sedang berjalan.

Penulis menggunakan Unified Modeling Language (UML) untuk merancang system pengolahan data transaksi dan invoice di PT. Wahana Eleksia Technology. UML berarti bahasa pemodelan standar (Muslihudin, 2016). UML menyediakan banyak diagram, penulis menggunakan use case diagram, dimana diagram tersebut digunakan untuk menggambarkan fungsi dari sebuah sistem informasi.

Dapat dijelaskan bahwa di dalam use case diagram ada beberapa pendefinisian yaitu aktor dan use case. Untuk aktor di definiskan sebagai admin dan user dimana kedua aktor memiliki hak akses yang berbeda. Adapun hak akses tersebut, jika level admin dapat mengakses keseluruhan menu hingga laporan sedangkan level user hanya dapat mengakses data admin dan tender. Selanjutnya use case ada data admin, data purchase order, data tender dan data invoice.

Hubungan antar data dapat digambarkan dalam bentuk ERD (Entity Relationship Diagram). Menurut (Rossa A. S., 2018) pemodelan basis data yang paling banyak digunakan adalah menggunakan Entity Relationship Diagram (ERD). ERD juga digunakan untuk pemodelan basis data relasional. Tujuan dari ERD ini adalah menunjukkan objek data dan relationship yang ada pada objek tersebut. Adapun ERD untuk PT. Wahana Eleksia Technology.

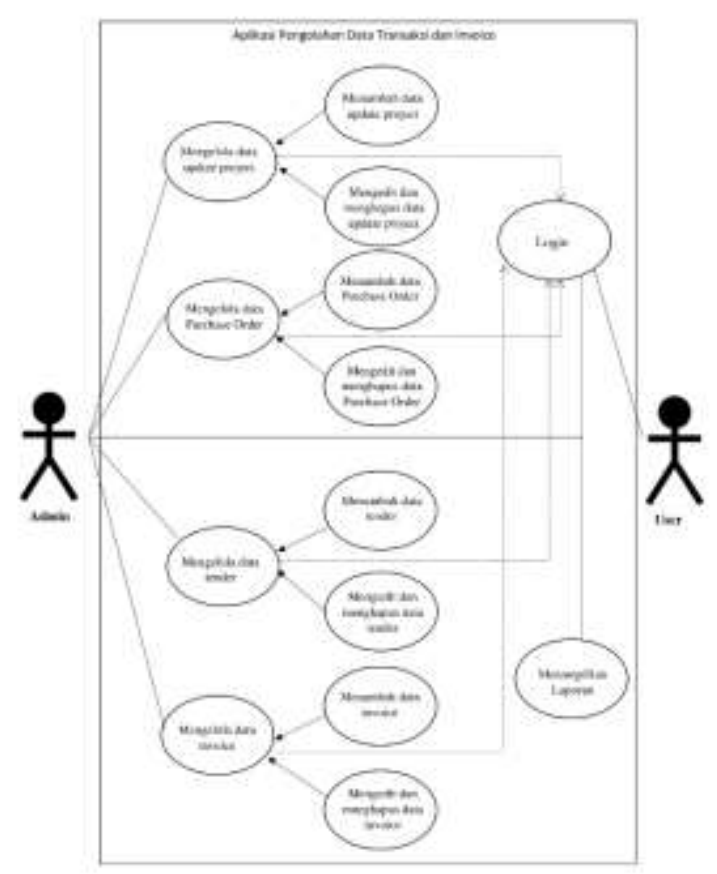

Gambar 1. Use Case Diagram

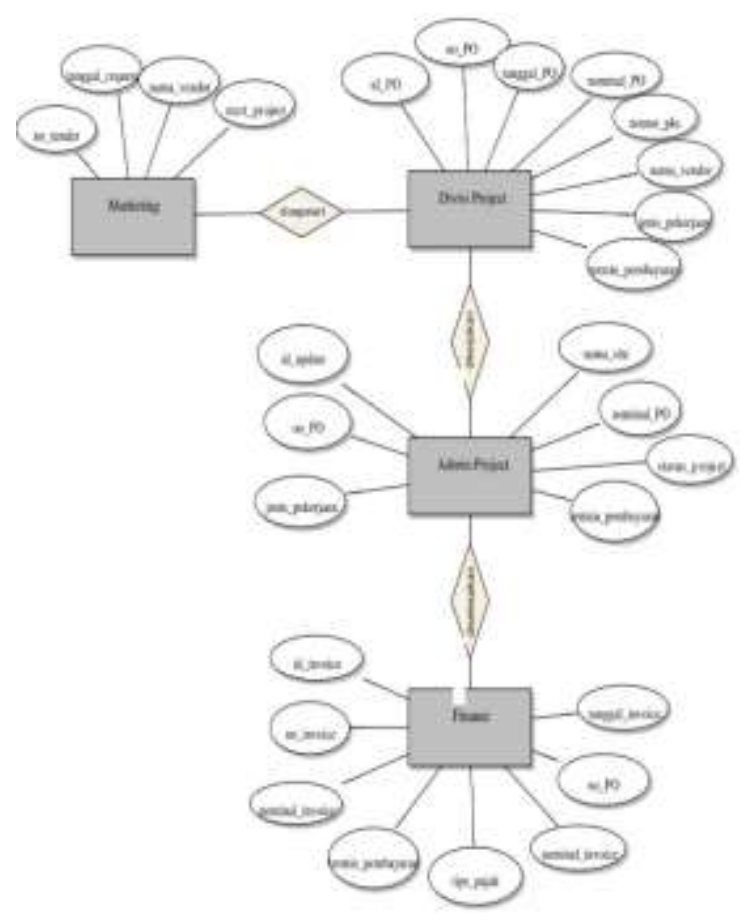

Gambar 2. ERD (Entity Relationship Diagram)

Berikut merupakan keseluruhan tampilan layar dan hasil pengujian pada software program yang telah di buat dengan bahasa pemrograman Java. 


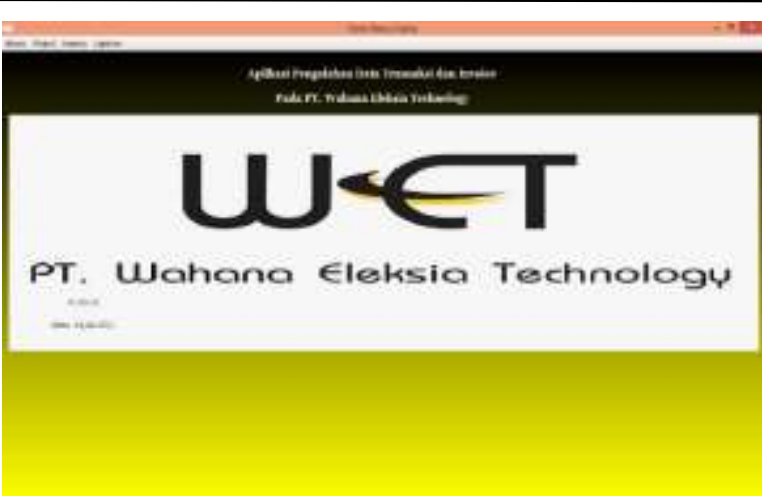

Gambar 3. Form Menu Utama

Pada layar utama tersedia menu bar yang terdiri dari menu Akses yang digunakan pada saat pengguna ingin login atau exit dari aplikasi, menu Project yang digunakan untuk memasukkan data yang berkaitan dengan data tender dan PO, menu finance yang digunakan untuk memasukkan data invoice dan update project. Menu laporan untuk mencetak semua laporan data transaksi dan invoice.

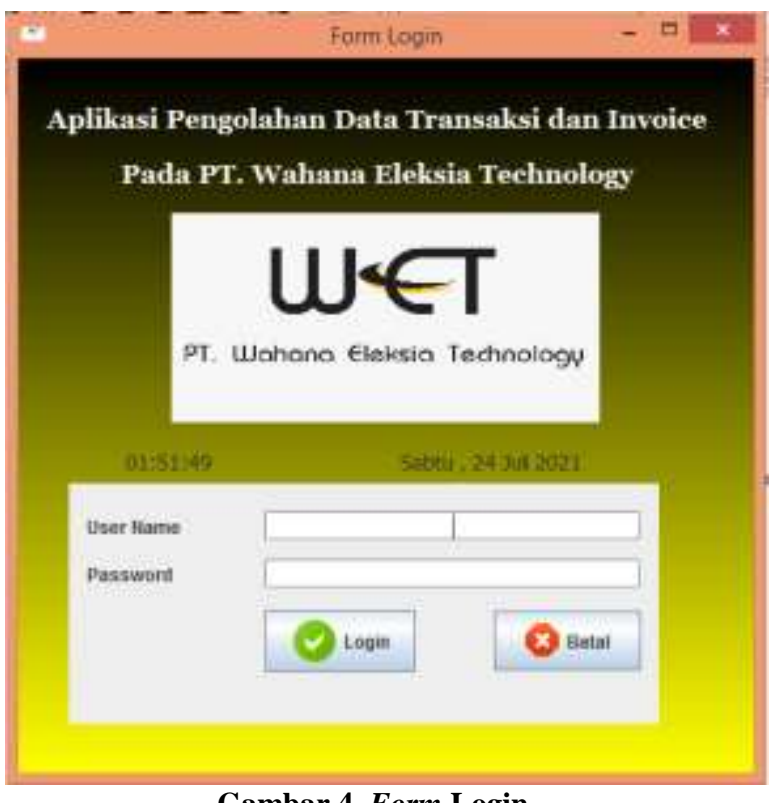

Gambar 4. Form Login

Layar di atas menampilkan tampilan awal program. Menu login merupakan kata kunci sebelum kita memasuki program utama. Agar tidak ada orang lain selain pihak yang berkepentingan yang dapat mengakses program ini. Jika user telah memasukkan nama pengguna dan password dengan benar, maka menu utama akan tampil.

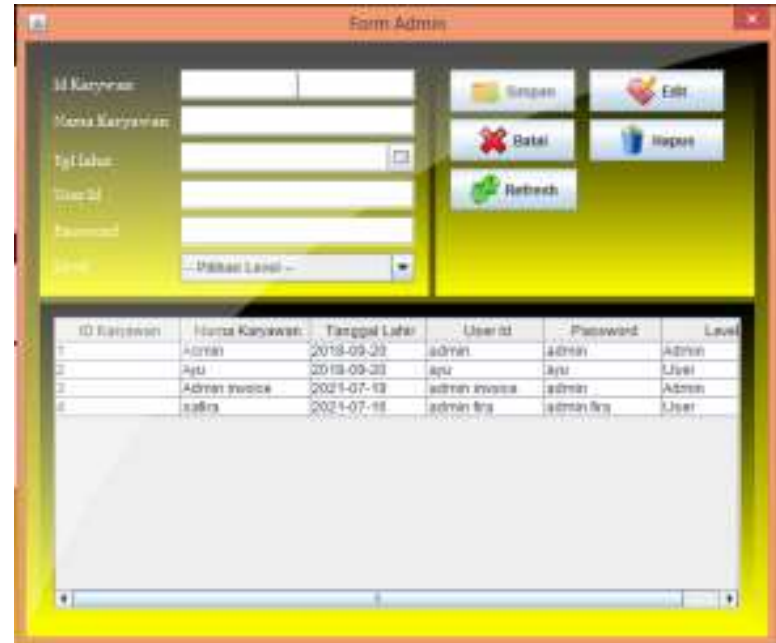

Gambar 5. Form Data Admin

Layar di atas menampilkan tampilan form admin. Form ini digunakan untuk melakukan registrasi user baru, yang dapat dibedakan menjadi 2 level yaitu admin dan user. Di mana 2 level itu memiliki hak akses yang berbeda.

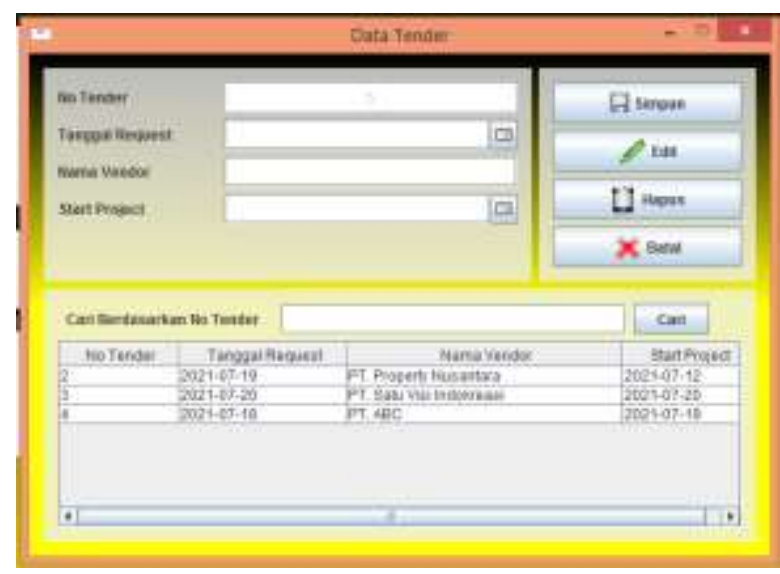

Gambar 6. Data Form Tender

Layar di atas menampilkan tampilan form data tender yang digunakan untuk memasukkan data tender baru dimana proyek baru akan dimulai. Pada form ini terdapat beberapa tombol yang berfungsi untuk menambahkan data tender yang baru, menyimpan semua kegiatan peng-input-an yang terjadi pada menu ini, membatalkan semua kegiatan penyimpanan yang telah dilakukan, dan mengeluarkan dari form data tender untuk kembali ke menu utama. 


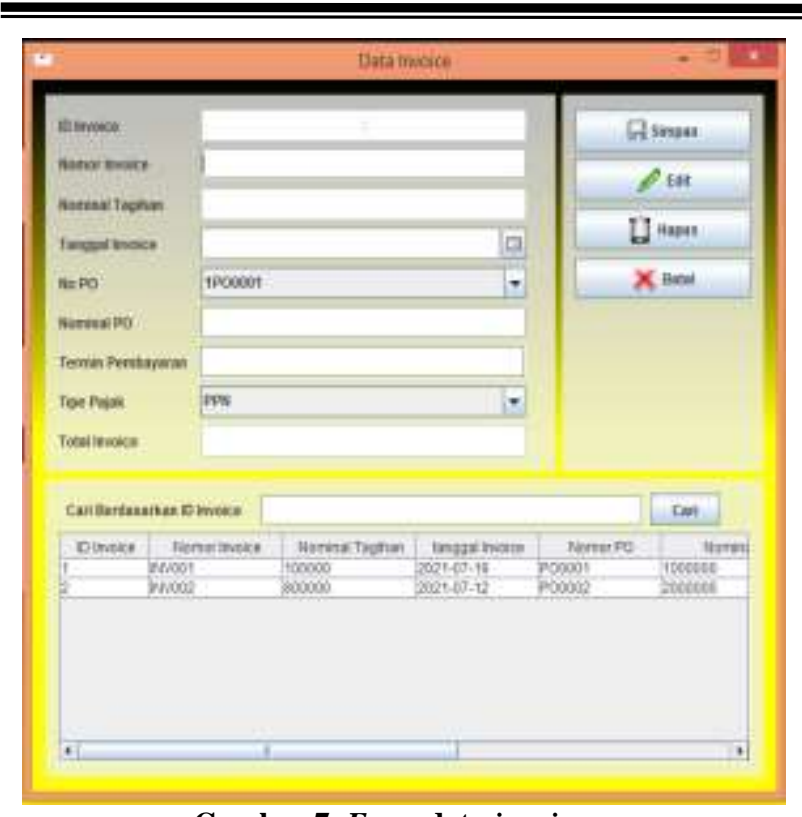

Gambar 7. Form data invoice

Layar di atas menampilkan tampilan form invoice memiliki beberapa tombol yang dapat digunakan untuk menambah, menyimpan, mengubah, membatalkan, dan menghapus semua file yang telah di-input. Ada juga tombol yang digunakan untuk keluar dan kembali ke tampilan menu utama. Di dalam form ini juga disedikan tombol pilihan untuk memasukan persentase tagihan dan tipe pajak.
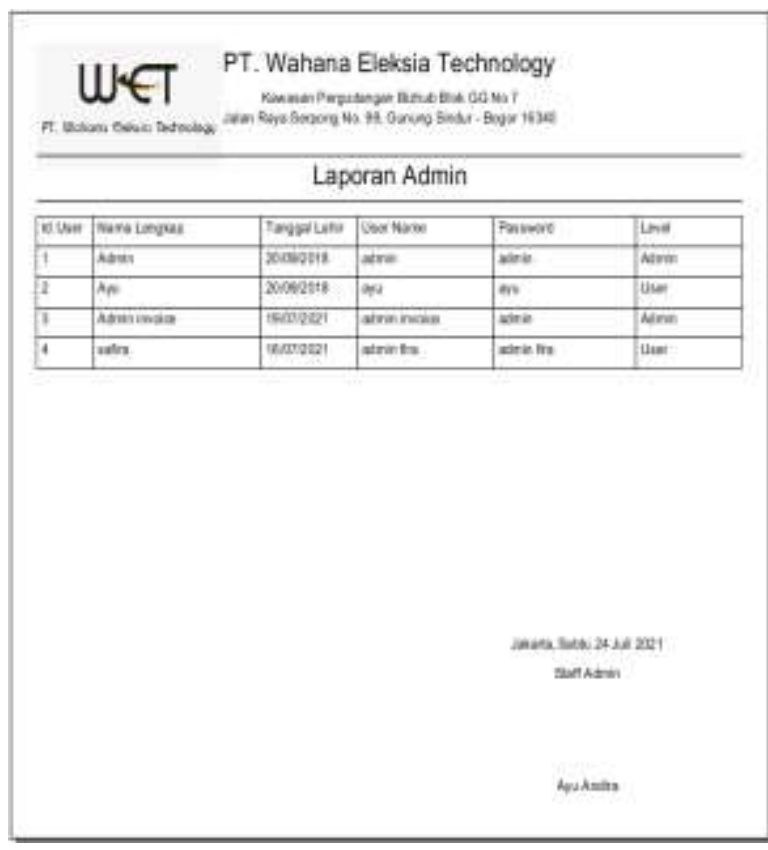

Gambar 8. Laporan Data Admin

Layar di atas menampilkan tampilan form laporan data admin pada layar form data admin digunakan untuk mencetak laporan nama, tanggal lahir, username dan password.

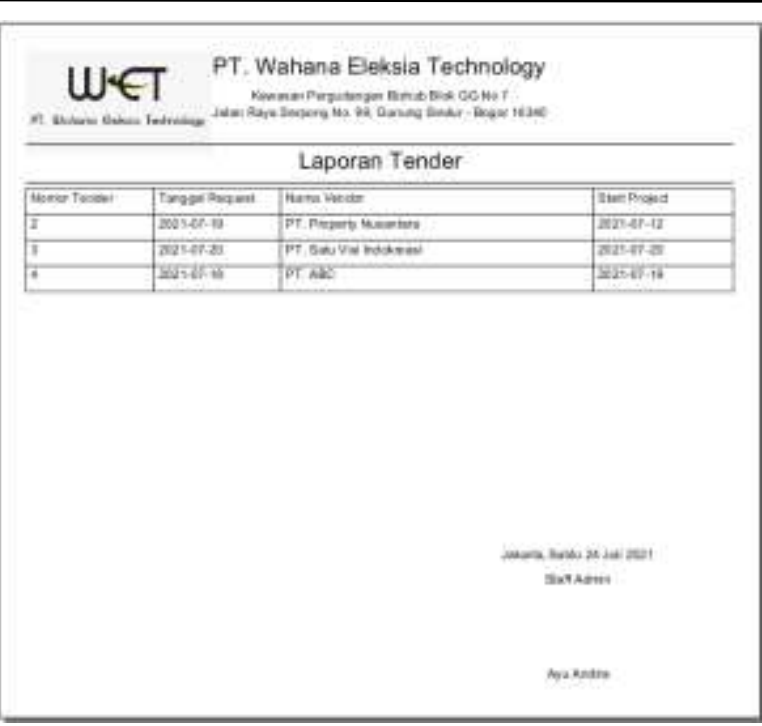

Gambar 9. Laporan Data Tender

Layar di atas menampilkan tampilan form laporan data tender. Pada layar form data tender digunakan untuk mencetak laporan data tender terdiri nomor tender, tanggal request, nama vendor dan start project.

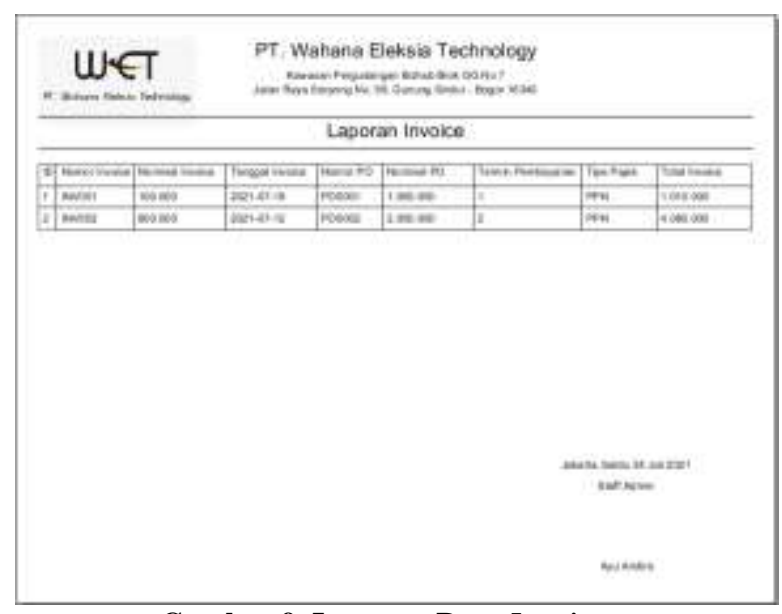

Gambar 9. Laporan Data Invoice

Layar di atas menampilkan tampilan form laporan data invoice. Pada layar form data invoice digunakan untuk mencetak laporan data invoice terdiri nomor invoice, nominal, nomor $\mathrm{PO}$, termin pembayaran, tipe pajak, total invoice.

\section{SIMPULAN DAN SARAN}

Berdasarkan hasil penelitian yang dilaksanakan, maka dapat disimpulkan beberapa hal mengenai sistem pengolahan data transaksi dan invoice di PT. Wahana Eleksia Technology adalah : aplikasi Pengolahan Data Transaksi dan Invoice ini dirancang sebagai solusi bagi pihak PT. Wahana Eleksia Technology untuk mengelola 
data proyek maupun data tansakasi invoice secara cepat, tepat dan akurat dibanding secara manual sehingga dalam mencapai pekerjaan dapat diselesaikan lebih maksimal. Sistem yang dirancang dapat mengakomodasi kebutuhan dalam mempermudah dan mempercepat kinerja staf admin dan finance yang bertugas dalam mengelola data transaksi. Selain itu, penyimpanan data-data proyek dan invoice dapat terorganisir dengan baik. Aplikasi Pengolahan Data Transaksi dan Invoice ini dibuat bersifat intern, artinya pengguna yang menggunakan program ini untuk kalangan tertentu yang memiliki hak akses menggunakan aplikasi ini yaitu Atasan, Admin dan Finance.

Agar penerapan sistem yang diusulkan ini dapat terwujud sesuai dengan harapan, maka penulis memberikan beberapa saran yang sebaiknya perlu diperhatikan : sebelum sistem baru dilaksanakan, sebaiknya admin project dan staf finance harus diberikan penjelasan sebaikbaiknya terlebih dahulu mengenai proses kerja sistem yang akan di terapkan, sehingga tidak terjadi kekeliruan dan kecanggungan dalam menggunakan aplikasi baru serta perlu dilakukan pelatihan penggunaan sistem tersebut agar mereka dapat mengetahui dan memahami cara kerja sistem yang terbaru. Keamanan sistem harus dijaga dengan cara memberikan kepercayaan pada personil yang bisa bertanggung jawab. Meskipun sistem sudah terkomputerisasi, ketelitian dalam memasukkan data perlu diperhatikan agar data yang sudah disimpan benar-benar merupakan salinan dari data sumber. Sistem ini diharapkan dapat dikembangkan dan dimanfaatkan sebagaimana mestinya tanpa adanya penyalahgunaan pada informasi yang diberikan.

Penulis menyadari bahwa masih banyaknya kekurangan dalam pembuatan Aplikasi Sistem Pengolahan Data Transaksi dan Invoice pada PT. Wahana Eleksia Technology. Maka dari itu, penulis berharap sistem ini dapat dikembangkan lebih baik lagi dan mendapatkan saran yang lebih baik lagi.

\section{DAFTAR PUSTAKA}

Asropudin, P. (2013). Kamus Teknologi Informasi Komunikasi. Titian Ilmu Bandung.

Hikmat, M. M. (2011). Metode penelitian: dalam perspektif ilmu komunikasi dan sastra. Graha Ilmu.

Mursyidi. (2010). Akuntansi Dasar. Ghalia Indonesia.

Muslihudin, M. (2016). Analisis dan Perancangan Sistem Informasi Menggunakan Model Terstruktur dan UML (A. Pramesta (ed.)). CV. Andi Offset.

Prasojo, M. (2011). Pengantar Sistem Informasi Manajemen. CV. Remadja Karya.

Pressman, R. S. (2012). Rekayasa perangkat lunak:pendekatan praktisi ed.7. Andi.

Rossa A. S., M. S. (2018). Rekayasa Perangkat Lunak: Terstruktur dan Berorientasi Objek Edisi Revisi. Informatika.

Susanto, A. (2013). Sistem Informasi Akuntansi. Lingga Jaya.

Sutabri, T. (2012). Konsep Sistem Informasi (I. Nastiti (ed.)). CV. Andi Offset.

Yuhefizar. (2012). Cara Mudah dan Murah Membangun dan Mengelola Website (Berkala Il). Graha Ilmu.

1025 | Perancangan Sistem Aplikasi Pengolahan Data Transaksi dan Invoice pada PT. Wahana Eleksia Technology Berbasis Java 